\title{
Stage IB Testicular Cancer AJCC v6 and v7
}

National Cancer Institute

\section{Source}

National Cancer Institute. Stage IB Testicular Cancer A/CC v6 and v7. NCI Thesaurus.

Code C6362.

Stage IB includes: (pT2, N0, M0, S0); (pT3, NO, MO, S0); (pT4, NO, MO, S0). pT 2: T umor limited to the testis and epididymis with vascular/lymphatic invasion, or tumor extending through the tunica albuginea with involvement of the tunica vaginalis. pT 3: T umor invades the spermatic cord with or without vascular/lymphatic invasion. PT 4: Tumor invades the scrotum with or without vascular/lymphatic invasion. N0: No regional lymph node metastasis. M0: No distant metastasis. S0: Marker study levels within normal limits. (AJCC 6th and 7th eds.) 